\title{
Immediate Loading of an Atrophied Maxilla Using the Principles of Cortically Fixed Titanium Hybrid Plates
}

\author{
Henri Diederich*, Alexandre Junqueira Marques, and Léo Guimarães Soares \\ Dental surgeon, Dental Clinic Henri Diederich, Luxembourg
}

Submission: September 19, 2016; Published: January 04, 2017

*Corresponding author: Henri Diederich, Dental surgeon, Dental Clinic Henri Diederich, 51 av Pasteur, L-2311Luxembourg, Europe, Tel: 00352621144664; Email: henri.diederich@pt.lu

\begin{abstract}
Replacing the dental arch evolved fixed prosthesis and later dental implants. Dental implants have intended to cover missing teeth in the maxilla and mandible. However, many areas have insufficient bone, and this is critical to success and prognosis. Therefore, this report case discusses an approach of implant treatment undertaken in a patient with pronounced maxillary atrophy using Pterygoid implants, biomaterials and a new model approach: the titanium Hybrid -Plates.
\end{abstract}

Keywords: Hybrid -Plates, Jaw atrophy, Tubero-pterygoid implants, Matri ${ }^{T M} b o n e$.

\section{Introduction}

The term osseointegration proposed by Branemark ${ }^{1}$ has developed an endosseous implant that forms an immobile connection with bone and has revolutionized oral rehabilitation with a significant advance in restorative dentistry [1]. Despite these success rates, some limitations have often found in sites implanted [1,2]. The need for a dental implant to completely address multiple physical and biological factors imposes huge constraints on the surgical and handling protocol [2].

Implants are the bestalternative to traditional prosthodontics; however, designing an implant-supported prosthesis with function and esthetic is very difficult to the dentists. Accuracy in planning and execution of surgical procedures is important in securing a high-success rate [3].

Dental implants eliminate adjacent teeth required for the placement of fixed partial denture. However, sufficient bone around implants is critical for success. In maxilla region, specifically in the maxillary sinus, reduction of bone height or pneumatised due to periodontal bone loss is a challenge for the placing of implants. In mandible, bone height has compromised; implant placement can lead to nerve damage [4].

Improvements in surgical reconstructive methods, as well as increased prosthetic demands, require a highly accurate diagnosis, planning, and placement2. New techniques of implants is emerging and search for an effective and adequate strength system to support prosthesis is necessary. Therefore, some authors developed and tested the efficacy of new implant (titanium Hybrid-Plates) for replacing the traditional system. The new implant system can easily overcome difficulties, it is economical, technically less sensitive for patient, and requires minimal arsenal for placement.

Therefore, this report case discusses an approach of implant treatment undertaken in a patient with pronounced maxillary atrophy using Pterygoid implants, biomaterials (Matri ${ }^{T M}$ bone) and a new model approach: the titanium Hybrid-Plates.

\section{Case Report}

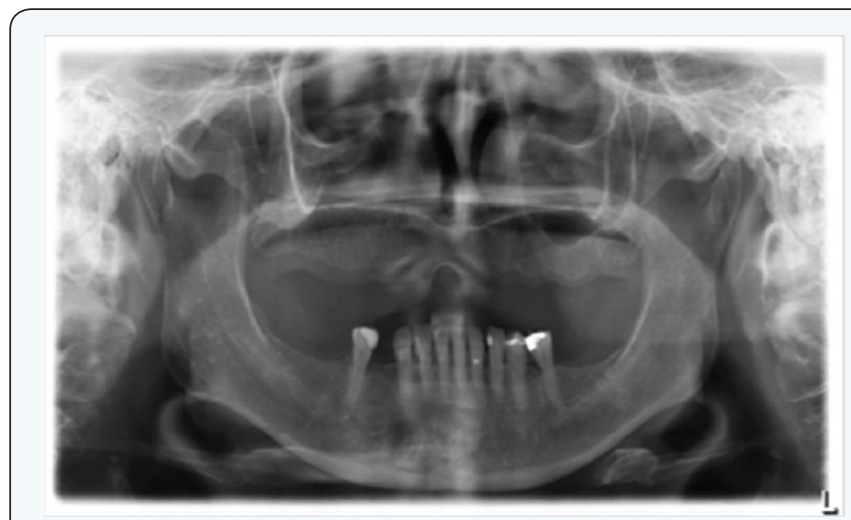

Figure 1: X-Ray of Patient.

A70-year-old female who has referred to the clinic for treatment with dental implants. The initial examination revealed that there was severe bone atrophy. The patient failed to adapt 
to the removable restoration and struggled with a gag reflex. In the maxilla, the resorption was progressive from a cranial and a caudal direction. This was compounded by the presence of an extremely narrow alveolar "knife" ridge that was not going to allow screw type implants to be used unless extensive bone grafting was performed (Figure 1).

The existing denture was used both for bite registration and to take a silicone impression, which provided the basis for implementing a temporary fixed restoration immediately after implant placement.
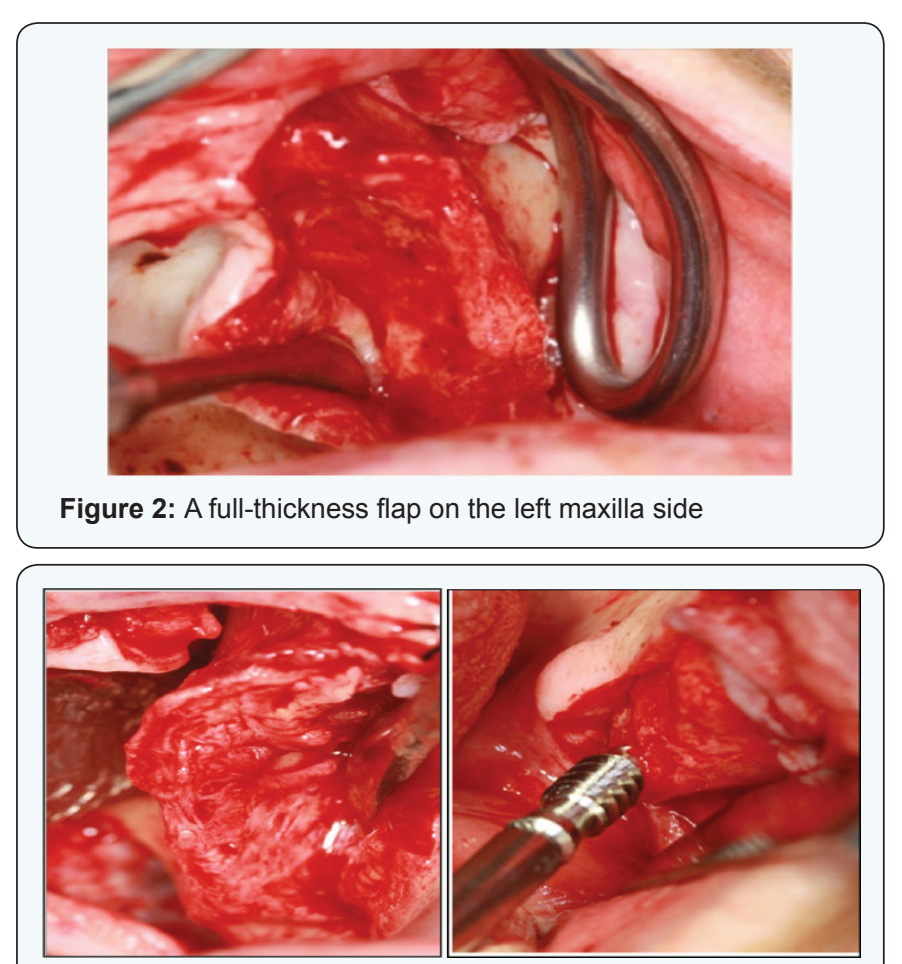

Figure 3: Pterygoid implant.

In the maxilla, a full-thickness flap was prepared from the left to the incisal centre and freed over a wide area for good exposure of the zygomatic bone and the palatine bone (Figure 2). At the left posterior tuberosity (approximately in the 28 region), a 19 $\mathrm{mm}$ long and 3. 5 diameter machined implant has inserted in the pterygoid plate to provide posterior cortical anchorage (Figure 3).

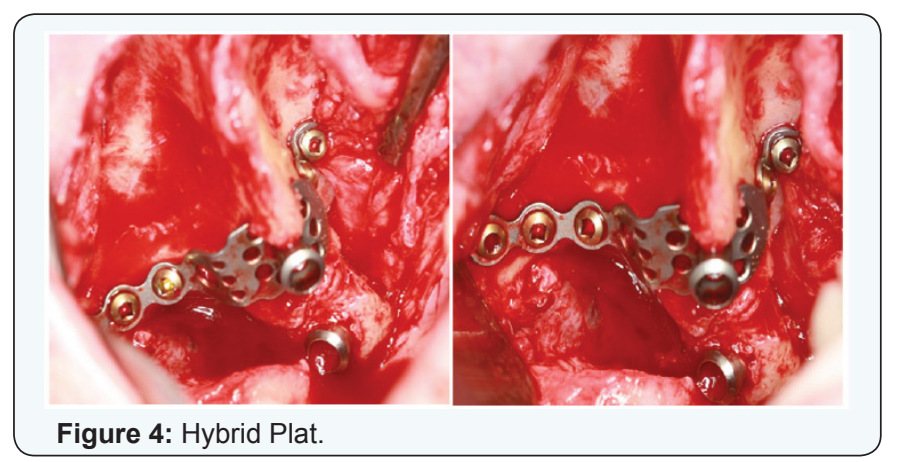

In view of the lack of bone at sites, 26 and 23-24 two hybridplates were inserted using several osteo-synthesis screws (Figure 4). These plates in titanium grade II can be bent as required to ensure that the implant fits the bone perfectly. In position 26 the length of the plate was $43 \mathrm{~mm}$ and $9 \mathrm{~mm}$ wide and in position 23 24 the plate was $41 \mathrm{~mm}$ long and $7 \mathrm{~mm}$ wide.Both plates were covered with Matri ${ }^{\text {TM }}$ bone which is aresorbable, osteoconductive bone substitute matrix consisting of hydroxyapatite, $B$-tricalcium phosphate and collagen which can be invaded with osteoblasts and thus resorbed partially within a few months (Figure 5).

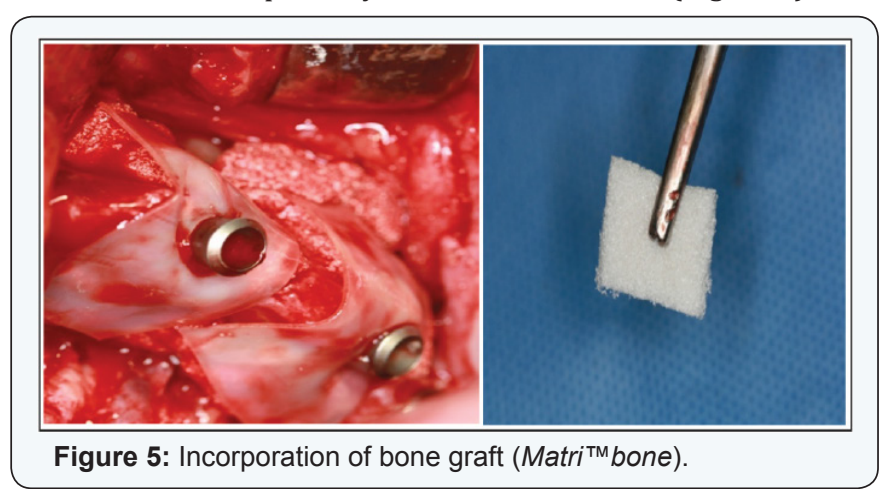

Following implant placement, closure was obtained using 3.0 silk sutures. Ultracaine anaesthetic $(5 \mathrm{ml})$ was administered and the bite registration re-taken. The procedure for the right side has duplicated, inserting a machined $4.5 / 17 \mathrm{~mm}$ implant in position 18 in the pterygoid plate (Figure 6).

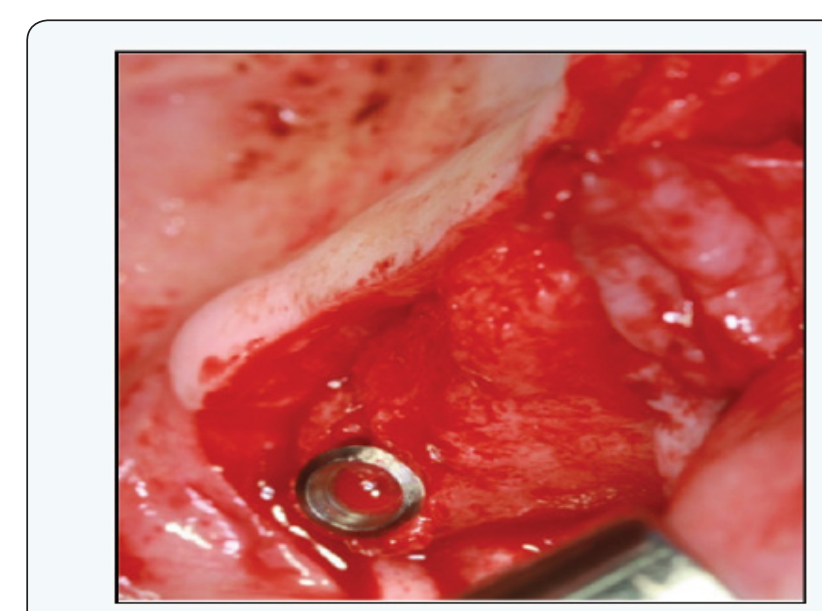

Figure 6: Pterygoid implant.

A hybrid plate has put in position $16,43 \mathrm{~mm}$ in length and 9 $\mathrm{mm}$ wide and another hybrid plate $41 \mathrm{~mm} 7 \mathrm{~mm}$ wide in position 12-13 have installed and fixed with osteo-synthesis screws. Both plates have covered with Matri ${ }^{\text {TM }}$ bone.

The patient received Penicillin Antibiotic cover (Augmentin $875 \mathrm{mg}$ twice a day for 10 days), $2 \mathrm{ml}$ injection of cortisone (Diprophos) in the masseter muscle and Ibuprofen for pain relief. A follow up appointment have made 5 days later, stitches haveremoved and bite registration was re-taken. 
Together with the Laboratory technician, the smile line was fixed and the colour of teeth chosen.

At a third appointment, 5 days later, the bridge was positioned and screwed in all positions with a torque of $15 \mathrm{~N} / \mathrm{cm}$ (Figure 7). Occlusion has checked and instructions for hygiene maintenance has given. Regular follow up checks were scheduled for 1,3 and then 6 months. The patient had no complications and she has rehabilitated within 10 days from the surgery. No bone graft or sinus-lift was required (Figure 8).

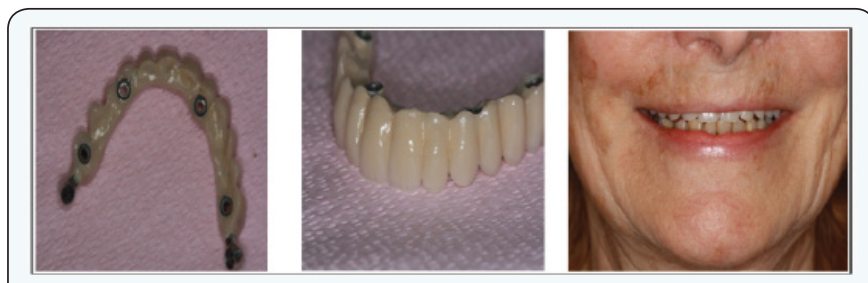

Figure 7: Finished metal resin bridge.

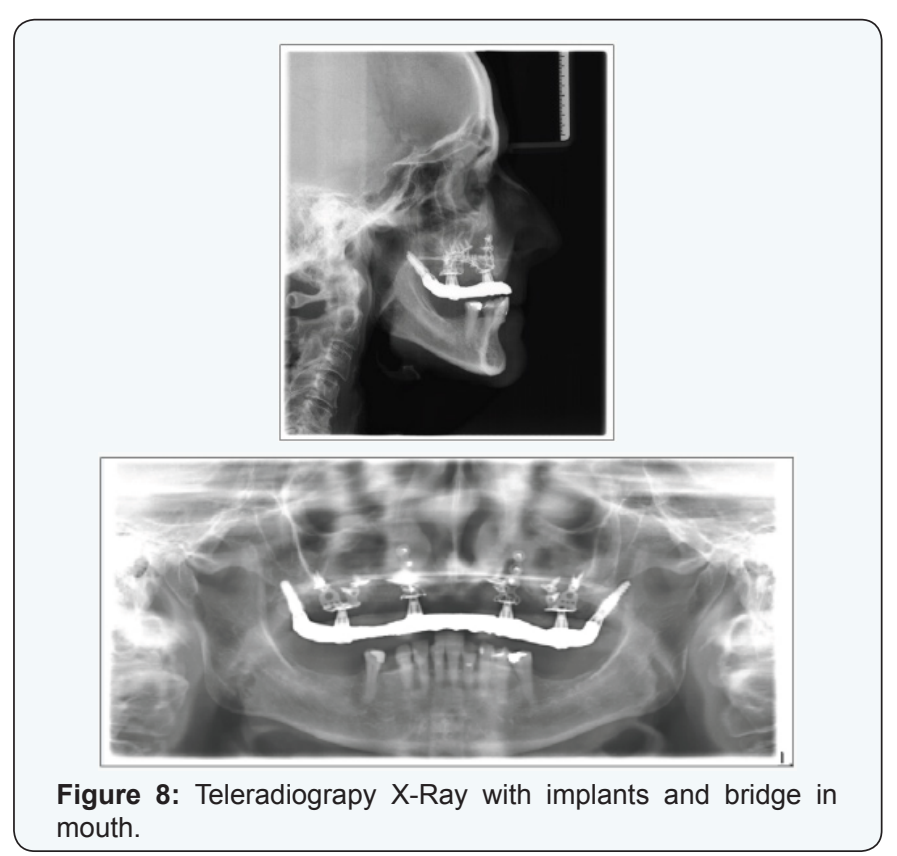

\section{Discussion}

The present report has shown a successful case of immediate loading of an atrophied maxilla with pterygoid and hybrid plates. The pterygoidimplants, same as used in this report case, have the advantage ofallowing anchorage in the posterior atrophied maxilla. According a literature review [5], 1053 implants into maxilla showed an average success of $90 \%$, and the authors concluded that pterygoidimplants have similar bone loss level tothose of conventional implants. Another two studies showed a viable alternativeto rehabilitate of posterior atrophic maxilla with pterygoid implants: in 1608 implants into the pterygomaxillary also found an average success of $90 \% 6$ and in evaluation of 68 pterygoid implants over 1year of loading found a success of $97 \%[6,7]$.

The hybrid implants, same as used in this report case, have tested in fivepatients [4], showed good stability, and minimum patient discomfort during 1-year postoperative period evaluation. The successful incorporation of bone grafts relies on following factors: surgical asepsis, soft-tissue coverage, graft space maintenance, graft immobilization, regional acceleratory phenomenon, host bone blood vessel and optimization of growth factors [3]. Matri ${ }^{\text {TM }}$ bone, same as used in this report case, showed good regeneration results and quickly obtain of sufficient density for bone implants [8] and, in two cases reported [9], generated a volume of excellent bone around the implants.

\section{Conclusion}

Advances in Cortical Implantology in Europe (particularly in France and Luxembourg) have provided alternative surgical options for the rehabilitation of certain types of patients whose prognosis was extremely poor or required highly invasive and long surgical procedures.

Therefore, the described surgical technique using Pterygoid implants, hybrid plates and biomaterials has increased the range of treatment options for some edentulous patients who could be unsuitable candidates for standard forms of treatment.

\section{References}

1. Bränemark PI, Breine U, Adell R, Hansson O, Lindström J, et al. (1969) Intra-osseous anchorage of dental prostheses. I. Experimental studies. Scand J PlastReconstrSurg 3(2): 81-100.

2. Mohammed Zaheer Kola, Altaf H Shah, Hesham S Khalil, Ahmed Mahmoud Rabah, Nehad Mohammed H Harby, et al. (2015) Surgical Templates for Dental Implant Positioning: current Knowledge and Clinical Perspectives. Niger J Surg 21(1): 1-5.

3. Misch CE (2007) Contemporary Implant Dentistry. ( $3^{\text {rd }}$ edn), Mosby Publications, St. Louis, Missouri.

4. Mani V, Sivaprasad KK, George A, Sankar Vinod V, Mathew M, et al. (2015) Hybrid Implant: A Novel Implant System. J Maxillofac Oral Surg 14(3): 720-727.

5. Candel E, Peñarrocha D, Peñarrocha M (2012) Rehabilitation of the atrophic posterior maxilla with pterygoid implants: a review. J Oral Implantol 38(Suppl 1): 461-466.

6. Balshi TJ, Wolfinger GJ, Slauch RW, Balshi SF (2013) A retrospective comparison of implants in the pterygomaxillary region: implant placement with two-stage, single-stage, and guided surgery protocols. Int J Oral Maxillofac Implants 28(1): 184-189.

7. Peñarrocha M, Carrillo C, Boronat A, Peñarrocha M (2009) Retrospective study of 68 implants placed in the pterygomaxillary region using drills and osteotomes. Int J Oral Maxillofac Implants 24(4): 720-726.

8. Roch JL (2011) Comblement sinusien: A propos d'un cas clinique utilisant une nouvel le préparation de phosphate tri calcique ( $\beta$ - TCP) Hydroxyapatite (HA)/Collagène ; le Matri' ${ }^{\mathrm{TM} B O N E . ~ C l i n i c ~ 32: ~ 537-542 . ~}$

9. Fromental R (2010) Rempart Bio - actif ${ }^{\circledR}$ péri - implantaire, intérêt du Matri $^{\text {TM }}$ bone, matériau de substitution osseuse. Implantologie. 
Your next submission with Juniper Publishers will reach you the below assets

- Quality Editorial service

- Swift Peer Review

- Reprints availability

- E-prints Service

- Manuscript Podcast for convenient understanding

- Global attainment for your research

- Manuscript accessibility in different formats (Pdf, E-pub, Full Text, Audio)

- Unceasing customer service

Track the below URL for one-step submission https://juniperpublishers.com/online-submission.php 